\title{
ANALISIS FAKTOR YANG MEMENGARUHI KEPUTUSAN INVESTASI (STUDI PADA MAHASISWI DI SURABAYA)
}

\author{
Ifanda Ogix Fridana ${ }^{1}$, Nadia Asandimitra ${ }^{2}$ \\ ${ }^{1}$ Jurusan Manajemen, Universitas Negeri Surabaya \\ Email: ifandafridana16080574055@mhs.unesa.ac.id \\ ${ }^{2}$ Jurusan Manajemen, Universitas Negeri Surabaya \\ Email:nadiaharyono@unesa.ac.id
}

Masuk : 28-07-2020, revisi: 21-09-2020, diterima untuk diterbitkan : 23-09-2020

\begin{abstract}
ABSTRAK
Investasi adalah kegiatan investasi aset untuk mendapatkan keuntungan dalam jangka waktu tertentu. Penelitian ini bertujuan untuk menganalisis faktor-faktor yang mempengaruhi keputusan investasi. Penelitian ini menggunakan jenis penelitian kuantitatif dengan jumlah sampel 230 responden dengan menggunakan metode analisis Structural Equation Model (SEM). Objek penelitian ini adalah mahasiswi di Surabaya yang memiliki galeri investasi di kampusnya. Studi ini berfokus pada jenis kelamin perempuan karena dalam empat tahun terakhir investor perempuan mengalami peningkatan yang signifikan dibandingkan dengan investor laki-laki, padahal tingkat pengetahuan keuangan perempuan lebih rendah dibandingkan laki-laki. Hasil penelitian ini menunjukkan bahwa literasi keuangan, overconfidence, herding, toleransi risiko dan persepsi risiko berpengaruh positif terhadap keputusan investasi. Hasil penelitian ini dapat membantu Galeri Investasi sebagai lembaga untuk sering melakukan sosialisasi seperti pemahaman finansial, manfaat berinvestasi, cara mengantisipasi risiko untuk berinvestasi sehingga pemahaman tentang investasi dapat menyeluruh dan dapat menarik calon investor baru nantinya.
\end{abstract}

Kata Kunci : pengetahuan keuangaan, percaya diri, ikut - ikutan, resiko persepsi, resiko toleransi, investor perempuan

\section{ABSTRACT}

Investment is an asset investment activity to get a profit within a certain period. This study aims to analyze the factors that influence investment decisions. This study uses quantitative research with a sample of 230 respondents using the analysis method of Structural Equation Model (SEM). The object of this research is female students in Surabaya who have an investment gallery on their campus. This study focuses on the female gender because in the last four years female investors have experienced a significant increase compared to male investors, even though the level of financial knowledge of women is lower than that of men. The results of this study indicate that financial literacy, overconfidence, herding, risk tolerance and risk perception have a positive effect on investment decisions. The results of this research can help the Investment Gallery as an institution to conduct socialization frequently such as financial understanding, the benefits of investing, how to anticipate risks for investment so that an understanding of investment can be comprehensive and can attract new potential investors later.

Keywords: financial literacy, overconfidence, herding, risk perception, risk tolerance, female investors

\section{PENDAHULUAN}

\section{Latar Belakang}

Pasar Modal ialah tempat yang digunakan investor dan emiten dalam transaksi jual beli obligasi, saham, reksadana, dan instrumen lainnya dalam jangka waktu lama (IDX). Keberadan pasar modal sebagai tempat melakukan investasi yang terjamin memberikan manfaat bagi investor untuk menanamkan modalnya. Investasi adalah menempatkan dana dimasa sekarang yang mengharapkan mendapat sebuah keuntungan di masa depan menurut Halim, (2005:4). Pertumbuhan investasi di Indonesia mengalami signifikansi kenaikan, hal tersebut terbukti dari adanya kenaikan Single Investor Identification (SID) menurut laporan (KSEI) yang mengalami kenaikan dari periode 2012 - 2018. Pada tahun 2018 kenaikan yang tinggi dari 1.122.688 menjadi 1.617.367, atau meningkat sejumlah 44,06\% (KSEI, 2018). Hal ini terjadi tidak lepas dari edukasi dan sosialisasi yang dilakukan kepada masyarakat dan peran Bursa Efek Indonesia 
(BEI) yang melakukan kerjasama dengan PERTI (Universitas) dalam melakukan pendirian Galeri Investasi. Provinsi Jawa Timur mempunyai galeri investasi terbanyak dengan 56 Galeri Investasi dan 18 Galeri Investasi berada di Universitas-universitas di Surabaya (IDX, 2019).

Menurut (KSEI, 2018) investor di Indonesia masih didominasi kalangan umur 21-30 tahun sejumlah 39,72\% yang dimana rentang umur 21-30 tahun didominasi oleh kalangan mahasiswa, hal ini menunjukkan bahwa mahasiswa sudah paham terhadap investasi. Sedangkan dilihat dari gender jumlah investor di Indonesia masih di dominasi oleh laki-laki akan tetapi golongan wanita bukan berarti tidak melakukan investasi. Hal ini dibuktikan dari data yang menunjukkan bahwa investor wanita tumbuh sejumlah 956\% menjadi 476.000 investor per 16 April 2018 dari empat tahun terakhir per Desember 2014 jumlahnya masih 44.700 investor, sedangkan investor laki-laki hanya tumbuh $710 \%$ dalam periode yang sama dari 77.000 per Desember 2014 menjadi 629.000 investor per16 April 2018 (KSEI, 2018). Investor wanita mengalami pertumbuhan yang signifikan walaupun menurut (OJK, 2016) tingkat pemahaman keuangaan wanita lebih rendah dibandingkan dengan laki - laki. Fenomena ini sejalan dengan penelitian (Putri \& Rahyuda, 2017) yang menyatakan wanita memiliki keputusan investasi lebih baik daripada laki-laki. Menurut (Putri \& Rahyuda, 2017) perbedaan gender berpengaruh signifikan terhadap keputusan investasi.

Keputusan investasi adalah pilihan yang dilakukan dalam mengumpulkan pendapatan dari suatu aset untuk mendapatkan keuntungan dimasa depan (Novianggie \& Asandimitra, 2019). Berdasarkan research gap penelitian terdahulu ada beberapa faktor yang memberi pengaruh pada keputusan investasi, diantaranya yaitu financial literacy, overconfidence, herding, risk tolerance, dan risk perception. Financial literacy adalah pemahaman mendasar terkait pengetahuan dan sikap dalam mengelola keuangan (Putri \& Rahyuda, 2017). Pemahaman keuangan yang baik akan membuat seseorang baik ketika mengambil keputusan dan sebaliknya. Hasil ini didukung oleh penelitian (Novianggie \& Asandimitra, 2019), (Putri \& Hamidi, 2019), (Sari, 2017), (Chen, Haiyang and Volpe, 2016) yang menyatakan pengaruh variabel financial literacy berpengaruh positif. Berbeda dengan penelitian yang dibuat oleh (Pradiksari \& Isbana, 2018), (Budiarto, 2017), (Ariani et al, 2016) dengan hasil financiali literacy tidak memberi pengaruh terhadap seseorang dalam memutuskan untuk investasi.

Overconfidence ialah sikap seseorang yang menganggap kemampuannya berada di atas rata-rata dan menganggap lebih hebat daripada orang lain (Pradhana, 2018). Seseorang yang memiliki overconfidence yang besar akan lebih condong berani dalam melakukan pengambilan tindakan dan sebaiknya. Hal ini didukung oleh penelitian (Pradiksari \& Isbana, 2018), (Noviangie \& Asandimitra, 2019), (Budiarto, 2017), (Pradhana, 2018) menyebutkan overconfidence mempunyai pengaruh pada keputusan investasi. Akan tetapi menurut (Rakhmatulloh \& Asandimitra, 2019), (Subash, 2012) menyebutkan overconfidence tidak mempunyai pengaruh pada keputusan invetasi. Herding merupakan perilaku investor yang cenderung mengikuti investor lain dalam berinvestasi tanpa melakukan analisis fundamental terlebih dahulu sehingga pasar yang terbentuk menjadi tidak efisien. Hal ini dapat memengaruhi seseorang terhadap keputusan yang akan ia lakukan walau keputusan orang lain tersebut belum tentu baik. (Gozalie \& Anastasia, 2015). Hal ini didukung oleh penelitian (Mutawally \& Asandimitra, 2019), (Shabgou \& Mousavi, 2016), (Subash, 2012) menyatakan herding berpengaruh positif sedangkan penelitian dari (Setiawan, Atahau, \& Robiyanto, 2018), (Gozalie \& Anastasia, 2015) yang menyatakan herding tidak memberi pengaruh terhadap seseorang dalam memutuskan untuk melakukan investasi. 
Risk tolerance ialah jumlah ketidak pastian yang diterima ketika keputusan diambil oleh individu (Putre, et al., 2017). Jikalau kuantitas dari risk tolerance seseorang bernilai tinggi maka semakin berani ketika memutuskan sesuatu hal. Pernyataan tersebut dikuatkan dari penelitian dari (Pradiksari \& Isbana, 2018), (Budiarto, 2017), (Wulandar \& Irmani, 2014) yang menyatakan riski tolerance berpegaruh pada seseorang dalam memutuskan untuk melakukan investasi. Berbanding terbalik dengan penelitian (Putra, Ananingtiyas, Sari, Dewi, \& Silvy, 2016) yang menyatakan risk tolerance tidak mempunyai pengaruh pada keputusan investasi. Risk perception ialah perspektif individu pada risiko yang akan dihadapinya. Individu yang mempunyai risk percption yang tinggi akan memutuskan dengan penuh pertimbangan dan sebaliknya. Hal ini didukung oleh penelitian dari (Novianggie \& Asandimitra, 2019) yang menyatakan risk perception mempunyai pengaruh pada keputusan investasi. akan tetapi berlawanan dengan penelitian dari (Mutawally \& Asandimitra, 2019) yang menyatakan risk perception tidak berpengaruh pada seseorang dalam memutuskan untuk investasi. Berdasar pada analisis yang telah dilakukan, maka penelitian ini mempunyai tujuan supaya mendapat informasi terkait pengaruh financial literacy, overconfidence, herding, risk tolerance, dan risk perception pada seseorang dalam memutuskan untuk investasi pada mahasiswi di Surabaya.

\section{LANDASAN TEORI DAN PENGEMBANGAN HIPOTESIS Standard Finance Theory}

Standard Finance Theory mengasumsikan bahwa investor normal digantikan dengan investor yang rasional dimana pengembalian yang diharapkan hanya ditentukan dengan resiko (Statman, 2008). Sikap rasional adalah sikap berfikir seseorang yang didasari dengan akal yang dapat dibuktikan dengan data dan fakta yang ada. Seorang investor yang memiliki sikap rasional, salah satunya dapat tercermin dalam pengambilan keputusan investasi yang didasari literasi keuangannya (Ariani, et al., 2016). Sehingga dalam penelitian ini financial literacy dianggap dapat mempengaruhi seseorang dalam mengambil keputusan berinvestasi.

\section{Behavioral Finance Theory}

Behavioral finance mengasumsikan bahwa investor melakukan tindakan berdasarkan kemampuan psikologi kognitifnya, artinya keputusan manusia tunduk pada psikologi kognitifnya (Waweru, et al., 2008). Berdasarkan penjelasan mengenai behavioral finance theory dapat di artikan bahwa tindakan seseorang di dasari pada psikologinya. Selain itu tindakan seseorang tidak selalu didasari oleh sikap rasionalnya saja, tetapi juga sikap irasionalnya.faktor - faktor yang yang memengaruhi behavioral finance ialah overconfidence, herding, risk tolerance dan risk perception yang digunakan sebagai variabel kontrol dalam penelitian ini.

\section{Pengaruh financial literacy terhadap keputusan investasi}

Literasi keuangan merupakan pengukuran terhadap pemahaman seseorang mengenai konsep keuangan, dan memiliki kemampuan dan keyakinan untuk mengatur keuangan pribadi melalui pengambilan keputusan jangka pendek yang tepat, perencanaan keuangan jangka panjang, serta memperhatikan kejadian dan kondisi ekonomi (OJK, 2017). Menurut (Budiarto, 2017) seorang investor yang memiliki pemahaman keuangan dengan baik dapat membuat keputusan investasi yang sesuai dengan harapannya. Berdasarkan hal tersebut, maka hipotesis yang dapat diajukan :

\section{H1 : Financial literacy berpengaruh terhadap keputusan investasi mahasiswi di Surabaya.}

\section{Pengaruh overconfidence terhadap keputusan investasi}

Overconfidence adalah perasaan terlalu percaya diri secara berlebihan dalam kemampuan atau pengetahuan yang dimiliki dalam melakukan investasi (Pradikasari \& Isbanah, 2018). Semakin tinggi tingkat kepercayaan diri seseorang maka akan sering seseorang tersebut melakukan 
trading, dan jika Overconfidence rendah maka seseorang akan berhat - hati dalam bertindak. Berdasarkan penjelasan diatas, maka hipotesis yang dapat diajukan :

\section{H2 : Overconfidence berpengaruh terhadap keputusan investasi mahasiswi di Surabaya.}

\section{Pengaruh herding terhadap keputusan investasi}

Herding merupakan perilaku yang dilakukan oleh investor dengan mengikuti investor lainnya. (Mutawally \& Asandimitra, 2019). Menurut (Setiawan et al., 2018) herding terjadi kepada investor bisa dikarenakan informasi yang sama antar investor sehingga mengambil keputusan yang sama, dan terjadi kepada investor yang memiliki informasi yang berbeda tetapi investor mengabaikan informasi miliknya dan mengikuti investor lainnya. Berdasarkan hal tersebut, maka hipotesis yang dapat diajukan :

\section{H3: Herding berpengaruh positif terhadap keputusan investasi mahasiswi di Surabaya.}

\section{Pengaruh risk tolerance terhadap keputusan investasi}

Risk tolerance atau toleransi risiko adalah tingkat kemampuan yang dapat anda terima dalam mengambil suatu risiko investasi (Wulandari \& Iramani, 2014). Setiap orang memiliki tingkat tolerance yang berbeda beda, perbedaan dalam memberikan toleransi risiko dapat disebabkan antara lain usia, status karir, sosial ekonomi, pendapatan, kekayaan dan jangka waktu prospek pendapatan. Berdasarkan hal tersebut, maka hipotesis yang dapat diajukan :

\section{H4 : Risk tolerance berpengaruh terhadap keputusan investasi mahasiswi di Surabaya.}

\section{Pengaruh risk perception terhadap keputusan investasi}

Risk perception merupakan penilaian seseorang pada situasi berisiko, penilaian tersebut sangat tergantung pada karakteristik psikologis dan keadaan orang tersebut (Pradikasari \& Isbanah, 2018). Jika seseorang mempunyai tingkat risk perception yang tinggi maka akan berhati-hati dalam mengambil keputusan investasi, sedangkan seseorang yang mempunyai tingkat risk perception yang rendah maka akan berani dalam mengambil keputusan karena telah memiliki pengalaman yang cukup banyak tentang investasi.(Pradikasari \& Isbanah, 2018). Aren \&Zengin(2016) berpendapat bahwa persepsi risiko mempengaruhi preferensi investasi individu. Berdasarkan hal tersebut, hipotesis yang dapat diajukan :

\section{H5 : Risk perception berpengaruh terhadap keputusan investasi mahasiswi di Surabaya.}

Berdasarkan hasil analisis penelitian terdahulu serta hipotesis yang telah ditentukan maka, model penelitian dapat dilihat pada gambar 1 .

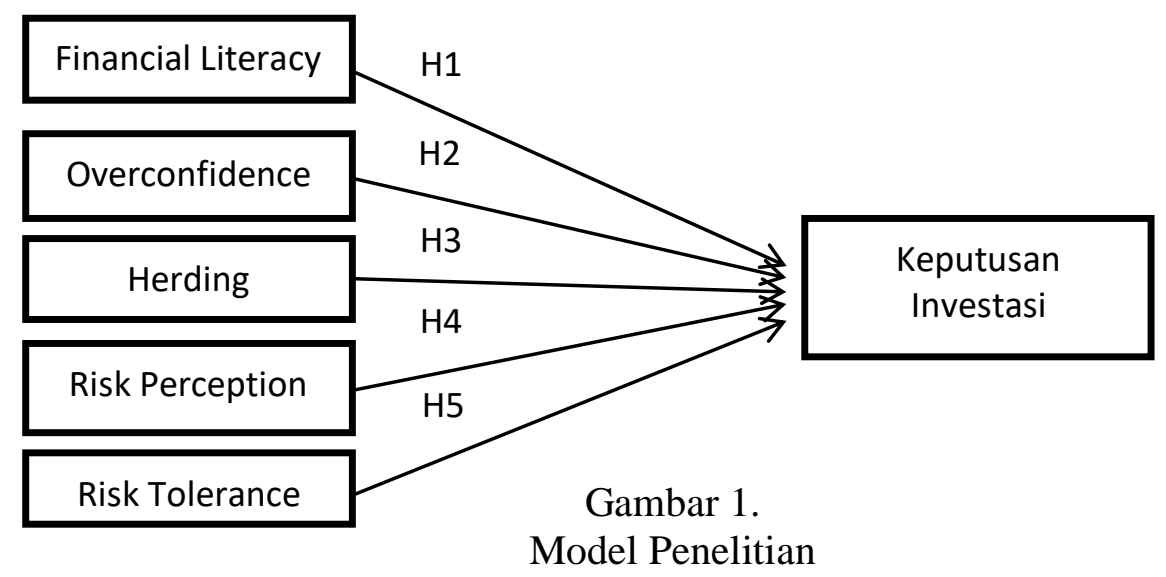




\section{METODE PENELITIAN}

Penelitian ini memakai penelitian konklusif kausalitas dengan jenis data kuantitatif. Data pada penelitian ini menggunakan data primer melalui kuesioner. Populasi dari penelitian ini ialah mahasiswi Galeri Investasi di Surabaya. Sampel penelitian ini ialah mahasiswi yang tergabung dengan Galeri Investasi di 17 perguruan tinggi di Surabaya. Kriteria responden ialah mahasiswi yang aktif di Galeri Investasi dan pernah melakukan transaksi di pasar modal.

Penelitian ini menggunakan Structural Equation Model (SEM) dengan program AMOS. Data responden yang terkumpul sejumlah 234 dengan 4 data responden tidak memenuhi kriteria. Selanjutnya dilakukan uji validitas dan reliabilitas untuk melihat dan memastikan bahwa item pernyataan yang digunakan dalam penelitian dapat mewakili variabel penelitian. Dimensi dan indikator yang digunakan untuk mengukur variabel financial literacy, overconfidence, herding, risk tolerance, risk perception dan keputusan investasi dalam penelitian ini merupakan dimensi dan indikator yang digunakan oleh beberapa peneliti sebelumnya dan telah disesuaikan dengan obyek penelitian (tabel 1).

Tabel 1 Dimensi dan Pengukuran Indikator Variabel

Sumber: Beberapa artikel (diolah penulis, 2020)

\begin{tabular}{|c|c|c|c|}
\hline Variabel & Peneliti & Dimensi & Indikator \\
\hline \multirow[t]{3}{*}{$\begin{array}{l}\text { Financial } \\
\text { literacy }\end{array}$} & $\begin{array}{l}\text { Chen } \\
\text { Volpe, } \\
\text { (1998) }\end{array}$ & $\begin{array}{l}\text { Basic } \\
\text { financial } \\
\text { concept }\end{array}$ & $\begin{array}{l}\text { Membeli barang yang memberikan diskon } \\
\text { Membeli barang yang harganya murah } \\
\text { Membeli barang yang bermerek } \\
\text { Mengalokasikan sebagian pendapatan untuk } \\
\text { investasi } \\
\text { Memilih kualitas dalam investasi } \\
\text { Berinvestasi untuk mencari keuntungan }\end{array}$ \\
\hline & & $\begin{array}{l}\text { Saving } \\
\text { and } \\
\text { Borrowing } \\
\text { Insurance }\end{array}$ & $\begin{array}{l}\text { Menabung untuk berjaga - jaga. } \\
\text { Menabung untuk tujuan masa depan } \\
\text { Memilih asuransi yang tepat }\end{array}$ \\
\hline & & Investment & $\begin{array}{l}\text { Mengalokasikan sebagian pendapatan untuk } \\
\text { investasi } \\
\text { Memilih kualitas dalam investasi } \\
\text { Berinvestasi untuk mencari keuntungan }\end{array}$ \\
\hline overconfidence & $\begin{array}{l}\text { Jannah \& } \\
\text { Ady }(2017)\end{array}$ & & $\begin{array}{l}\text { Percaya pada pengetahuan dan kemampuan yang } \\
\text { dimiliki dibandingkan investor lain. } \\
\text { Bisa memprediksi kejadian kejadian yang akan } \\
\text { datang. } \\
\text { Risiko yang di timbulkan tidak terlalu bearti. } \\
\text { Sangat yakin akan mendapatkan keuntungan } \\
\text { yang besar. } \\
\text { Sangat yakin dengan pilihan investasi yang } \\
\text { dilakukan. }\end{array}$ \\
\hline Herding & $\begin{array}{l}\text { Subash } \\
(2012)\end{array}$ & & $\begin{array}{l}\text { Pengambilan keputusan berdasarkan suara } \\
\text { mayoritas. } \\
\text { Kurangnya keputusan yang dibuat secara } \\
\text { individual. }\end{array}$ \\
\hline Risk Tolerance & $\begin{array}{l}\text { (Budiarto, } \\
\text { 2017) }\end{array}$ & & $\begin{array}{l}\text { penggunaan pendapatan untuk investasi yang } \\
\text { bersifat spekulasi }\end{array}$ \\
\hline
\end{tabular}




\begin{tabular}{|c|c|c|}
\hline & & $\begin{array}{l}\text { Pembelian instrumen tanpa pertimbangan } \\
\text { Investasi pada kegiatan yang memberikan return } \\
\text { besar. }\end{array}$ \\
\hline \multirow[t]{2}{*}{$\begin{array}{l}\text { Risk } \\
\text { perception }\end{array}$} & \multirow{2}{*}{$\begin{array}{l}\text { (Wulandari } \\
\& \text { Iramani, } \\
\text { 2014) }\end{array}$} & $\begin{array}{l}\text { Investasitanpapertimbangandantanpajaminan, } \\
\text { serta }\end{array}$ \\
\hline & & $\begin{array}{l}\text { Penggunaanpendapatanuntukinvestasi yang } \\
\text { berisiko. }\end{array}$ \\
\hline \multirow{8}{*}{$\begin{array}{l}\text { Keputusan } \\
\text { Investasi }\end{array}$} & \multirow{8}{*}{$\begin{array}{l}\text { Ullah } \\
\text { (2015) }\end{array}$} & Uang adalah tujuan paling penting dalam hidup \\
\hline & & $\begin{array}{l}\text { Merasa lebih puas jika menghemat uang } \\
\text { daripada menginvestaskannya }\end{array}$ \\
\hline & & $\begin{array}{l}\text { Pasar saham tidak dapat diprediksi sehingga } \\
\text { tidak melakukan investasi }\end{array}$ \\
\hline & & $\begin{array}{l}\text { Menginvestasikan uang dalam jumlah yang } \\
\text { banyak pada saham }\end{array}$ \\
\hline & & $\begin{array}{l}\text { Tidak pastinya pasar menjadi alasan tidak } \\
\text { membeli saham. }\end{array}$ \\
\hline & & Lebih suka menyimpan uang karena tidak tahu \\
\hline & & kapan akan butuh uang \\
\hline & & Menganggarkan uang saya dengan baik \\
\hline
\end{tabular}

\section{HASIL DAN PEMBAHASAN}

Uji validitas dan reliabilitas dilakukan untuk memastikan bahwa item pernyataan yang digunakan dalam penelitian layak untuk mewakili variabel penelitian. Hasil uji validitas dan reliabilitas dalam penelitian ini dinyaratakan valid dan reliabel. Dinyatakan valid karena nilai estimate standardized regression weight menunjukkan seluruh item pernyataan memiliki nilai diatas 0,05 dan dinyatakan reliabel karena nilai Construct Reliability $(\mathrm{CR})>0,60$.

Hasil uji oulier pada penelitian ini menunjukkan bahwa tidak terjadi outlier sengan melihat nilai mahalanobis distance menggunakan kriteria p1 dan p2 >0,05 bahwa dari 230 responden tidak terdapat nilai yang melebihi batas kriteria. Selanjutnya untuk uji normalitas menunjukkan hasil bahwa nilai critical ratio skewness value dan critical ratio kuortis berada pada rentang $\pm 2,58$. Berdasarkan hasil uji outlier dan normalitas maka data yang diperoleh layak untuk digunakan dalam uji selanjutnya.

Tabel 1 UJI GOODNESS OF FIT

Sumber: Output Amos (data diolah penulis, 2020)

\begin{tabular}{llll}
\hline Goodness of fit Indices & Batas & Hasil & Keterangan \\
\hline GFI & $>0,900$ & 0,868 & MARGINAL \\
\hline AGFI & $>0,900$ & 0,962 & BAIK \\
\hline TLI & $>0,900$ & 0,957 & BAIK \\
\hline NFI & $>0,900$ & 0,831 & MARGINAL \\
\hline RMSEA & $>0,800$ & 1,07 & BAIK \\
\hline
\end{tabular}

Berdasarkan tabel 1 diatas, uji kelayakan model dilakukan menggunakan uji goodness of fit indices dengan melihat nilai GFI, AGFI, TLI, NFI, dan RMSEA. Berdasarkan hasil pengujian tersebut diperoleh hasil bahwa terdapat 3 kriteria yang dinyatakan baik yaitu AGFI dengan nilai $0,962>(0,900)$, TLI dengan nilai $0,957>(0,900)$ dan RMSEA dengan nilai $1,07>(0,900)$, sedang 2 lainnya marginal yaitu GFI dengan nilai 0,868 (batas > 0,900) dan NFI dengan nilai 
0,831 (batas > 0,900). Sehingga model penelitian ini diterima dan layak untuk dilakukan dalam uji selanjutnya.

Tabel 2 Hasil Uji Hipotesis

Sumber : Output Amos (data diolah penulis, 2020)

\begin{tabular}{lllllll} 
& & & Estimate & S.E. & C.R. & P \\
\hline $\mathrm{FL}$ & $\rightarrow$ & KI & 0,211 & 0,079 & 2,66 & 0,008 \\
\hline $\mathrm{O}$ & $\longrightarrow$ & KI & 0,212 & 0,098 & 2,158 & 0,031 \\
\hline $\mathrm{H}$ & $\longrightarrow$ & KI & 0,073 & 0,036 & 2,039 & 0,041 \\
\hline $\mathrm{RT}$ & $\longrightarrow$ & KI & 0,606 & 0,276 & 2,201 & 0,028 \\
\hline $\mathrm{RP}$ & $\longrightarrow$ & KI & 0,232 & 0,049 & 4,713 & $* * *$ \\
\hline
\end{tabular}

\section{Pengaruh Financial Literacy terhadap Keputusan Investasi}

Uji hipotesis menunjukan probabilitas signifikan senilai ,008 yang lebih kecil dari 0,05 yang artinya variabel financial literacy berpengaruh pada seseorang dalam memutuskan untuk investasi, hasil tersebut sejalan dengan standard finance theory yang menyebutkan seorang melakukan keputusan berdasarkan tindaakan yang rasioanl. Penyebab financial literacy berpengaruh karena responden dalam penelitian ini adalah mahasiswi yang memiliki tingkat pemahaman keuangan yang tinggi dengan presentase sejumlah 98\%. Dilihat dari data karakteritik responden yang mayoritas memiliki penghasilan dengan rentang 1.000 .000 2.000.000 dimana dengan rentang penghasilan tersebut membuat mahasiswi belajar bagaimana cara mengelola penghasilan tersebut untuk kebutuhan, keinginan dan investasi untuk mendapatkan keuntungan. Hasil penelitian berpengaruh ini sejalan dengan penelitian (Novianggie \& Asandimitra, 2019), (Rasyid, Linda, Patrisia, Fitra, \& Susanti, 2018), dan (Putri \& Hamidi, 2019) menyatakan financial literacy berpengaruh karena investor memiliki pengetahuan dan informasi yang dapat digunakan untuk melakukan investasi.

\section{Pengaruh Ovrconfidence Terhadap Keputusan Investasi}

Berdasarkan hasil uji hipotesis yang dilakukan menunjukan overconfidence berpengaruh terhadap keputusan investasi, hal ini dibuktikan dengan nilai probabilitas overconfidence sebesar 0,032 lebih kecil dari 0,05. Hal ini disebabkan responden adalah mahasiswi yang memiliki kepercayaan diri yang tinggi dikarenakan memiliki pengalaman dan pengetahuan dibidang pengelolahan keuangan. Hasil ini sejalan dengan behavioral finance theory yang menyatakan seseorang yang bertindak irasional memiliki kepercayaan diri yang berlebih terhadap kemampuan dan pengalaman yang dimiliki dan menganggap rendah terhadap risiko yang akan dihadapinya. Hasil penenlitian ini sejalan dengan penelitian (Pradikasari \& Isbanah, 2018), (Budiarto, 2017) dan (Novianggie \& Asandimitra, 2019) yang menyatakan bahwa semakin percaya diri seseorang akan membuat seseorang berani dalam membuat tindakan untuk melakukan investasi.

\section{Pengaruh Herding Terhadap Keputusan Investasi}

Berdasarkan hasil uji hipotesis herding berpengaruh terhadap keputusan investasi dengaan nilai probabilitas sebesar 0,041. Hal ini sejalan dengan behavioral finance theory yang menyatakan seseorang bertindak tidak selalu bersifat rasional tetai juga irasional. Responden dalam penelitian ini memang memiliki pengetahuan keuangan yang baik, tetapi dalam mengambil keputusan masih ikut dengan investor lainnya dikarenakan informasi satu investor dan investor yang lainnya terkadang berbeda dan tingkat pengalaman tiap investor juga berbeda, sehingga 
responden masih ikut ikutan investor yang lainnya dalam mengambil keputusan. Hasil penelitian ini searah dengan penelitian (Mutawally \& Asandimitra, 2019) dan (Shabgou \& Mousavi, 2016) yang mengungkapkan bahwasannya herding berpengruh terhadap keputusan investasi.

\section{Pengaruh Risk Tolerance Terhadap Keputusan Investasi}

Hasil uji hipotesis menunjukan nilai probabilitas risk tolerance sebesar 0,028 $(<0,05)$. Hasil ini menunjukan bahwa risk tolerance berpengaruh terhadap keputusan investasi. Hal ini sesuai dengan behavioral finance theory yang menyatakan bahwa psikologi seseorang mempunyai pengaruh pada keputusan investasi seseorang. Risk tolerance berpengaruh karena responden pada penelitian ini tergolong tipe risk neutral yang dimana responden dalam memandang risiko yang ada sesuai dengan return yang diterimanya. Responden dalam hal ini cenderung melihat keseimbangan antara return yang didapat dan risiko yang harus dihadapi. Hasil penelitian ini searah dengan penelitian (Pradikasari \& Isbanah, 2018) dan (Budiarto, 2017) yang menyatakan risk tolernce mempunyai pengaruh pada keputusan investasi.

\section{Pengaruh Risk Perception Terhadap Keputusan Investasi}

Hasil uji hipotesis menunjukan risk perception berpengaruh terhadap keputusan investasi hal ini didukung dengan hasil probabilitas dari risk perception sebesar 0,000. Hal ini sesuai dengan behavioral finance theory yang menyatakan tingkat psikologi seseorang berpengauh terhadap keputusan investasi seseorang. Risk perception merupakan pikiran, kepercayaan, dan konstruk seorang investor terhadap kejadian-kejadian negative yang mungkin terjadi pada investasi yang akan dilakukan. Apabila seseorang memiliki risk perception yang tinggi biasanya mempunyai sikap yang tidak gegabah. hal inidikarenakan responden mengambil tindakan dengan penuh pertimbangandan informsi yang dimilikinya. Hasil penelitian ini selaras denggan penelitian (Novianggie \& Asandimitra, 2019) dan (Wulandari \& Iramani, 2014) yang menyatakan bahwa risk prception mempunyai pengaruh pada keputusan investasi.

\section{KESIMPULAN DAN SARAN}

\section{Kesimpulan}

Berdasarkan hasil penelitian dan hasil pembahasan dapat disimpulkan bahwa adanya pengaruh variabel financial literacy, overconfidence, herding, risk tolerance dan risk perception terhadap keputusan investasi pada mahasiswi di Surabaya. Hal ini disebabkan responden pada penelitian ini memiliki pengetahuan keuangan yang baik, kepercayaan diri yang tinggi dala mengambil keputusan, memiliki orang ebagai acuan dalam mengambil tindakan, berhati hati dalam mengambil keputusan dan melihat risiko ketika memutuskan untuk berinvestasi. Implikasi teoritis penelitian ini sejalan dengan standard finance theory dimana responden mengambil keputusan dengan sikap rasional. Implikasi praktis penelitian ini adalah hasil penelitian dapat digunakan sebagai acuan bagi investor saat mengambil keputusan investasi agar investor memahami financial literacy, risk tolerance dan risk perception saat mengambil keputusan dan jangan mengesampingkan kepercayaan diri individu maupun mengikuti investor lain dalam mengambil keputusan.

\section{Saran}

Hasil penlitian ini dapat membantu bagi Galeri Investasi sebagai lembaga agar sering melakukan sosialisasi seperti pemahaman keuangan, keuntungan melakukan investasi, cara mengantisipasi risiko untuk investasi sehingga pemahaman tentang investasi bisa menyeluruh dan dapat menjaring calon - calon investor baru nantinya. Hasil ini juga dapat digunakan oleh investor agar menambah wawasan dan mencari informasi untuk melakukan analisis teknikal dan fundamental sebelum melakukan keputusan nvestasi, sehingga kedepannya investor tidak takut dalam 
mengambil keputusan investasi dan memperoleh keuntungan yang diinginkan. Sedangkan untuk peneliti selanjutnya hasil penelitian ini bisa dibuat referensi dan jika mengambil tema yang sama bisa menambahkan variabel lainnya seperti pengalaman investasi, social relevance, advocate recommendation atau variabel variabel yang jarang di teliti oleh peneliti - peneliti sebelumnya.

\section{REFERENSI}

Aren, S., \& Zengin, A. N. (2016). Influence of Financial Literacy and Risk Perception on Choice of Investment. Procedia - Social and Behavioral Sciences, 235, 656-663. https://doi.org/10.1016/j.sbspro.2016.11.047

Ariani et al. (2016). Locus of Control, Dan Etnis Terhadap Pengambilan Keputusan Investasi. Journal of Business and Banking, 5 Number2, 257-270. https://doi.org/10.14414/jbb.v5i2.550

Budiarto, A. (2017). Pengaruh Financial Literacy, Overconfidence, Regret Aversion Bias, dan Risk Tolerance Terhadap Keputusan Investasi (Studi pada investor PT. Sucorinvest Central Gani Galeri Investasi BEI Universitas Negeri Surabaya). Jurnal Ilmu Manajemen (JIM), 5(2), 1-9.

Chen, Haiyang and Volpe, R. P. (2016). An Analysis of Personal Financial Literacy Among College Students. Zhongguo Jiguang/Chinese Journal of Lasers, 43(8), 107-128. https://doi.org/10.3788/CJL201643.0811001

Gozalie, S., \& Anastasia, N. (2015). Pengaruh Perilaku Heuristics dan Herding Terhadap Pengambilan Keputusan Investasi Properti Hunian. Finesta, 3(2), 28-32.

IDX. (2019). Data galeri investasi bei. (1).

Jannah, W., \& Ady, S. U. (2017). Analisis Fundamental, Suku Bunga, Dan Overconfidence Terhadap Pengambilan Keputusan Investasi Pada Investor Di Surabaya. Jurnal Bisnis Dan Manajemen, 1(2), 138-156. https://doi.org/http://dx.doi.org/10.25139/ekt.v0i0.338

KSEI. (2018). Berita Pers 21 Tahun KSEI: Inovasi Untuk Kenyamanan Transaksi di Pasar Modal. Www.Ksei.Co.Id, 2-3. Retrieved from www.ksei.co.id/.../156_berita_pers_21_tahun_ksei_inovasi_untuk_kenyamanan_transaks i_di_pasar_modal

Mutawally, F. W., \& Asandimitra, N. (2019). Pengaruh Financial Literacy, Risk Perception, Behavioral Finance Dan Pengalaman Investasi Terhadap Keputusan Investasi Mahasiswa Surabaya. Jurnal Ilmu Manajemen, 7, 942-953.

Novianggie, V., \& Asandimitra, N. (2019). The Influence of Behavioral Bias, Cognitive Bias, and Emotional Bias on Investment Decision for College Students with Financial Literacy as the Moderating Variable. International Journal of Academic Research in Accounting, Finance and Management Sciences, 9(2), 92-107. https://doi.org/10.6007/IJARAFMS/v9-i2/6044

OJK. (2016). SNLK. 300.

OJK. (2017). Strategi Nasional Literasi Keuangan Indonesia (Revisit 2017). Otoritas Jasa Keuangan, 1-99.

Pradhana, R. W. (2018). Pengaruh Financial Literacy, Cognitive Bias, dan Emotional Bias terhadap Keputusan Investasi (Studi pada Investor Galeri Investasi Universitas Negeri Surabaya). Jurnal Ilmu Manajemen (JIM), 6(3), 108-117.

Pradikasari, E., \& Isbanah, Y. (2018). Pengaruh Financial Literacy, Illusion of Control, Overconfidence, Risk Tolerance, dan Risk Perception Terhadap Keputusan Investasi Pada Mahasiswa di Kota Surabaya. Jurnal Ilmu Manajemen (JIM), 6(4), 424-434.

Putra, I. P. S., Ananingtiyas, H., Sari, D. R., Dewi, A. S., \& Silvy, M. (2016). Experienced Regret, dan Risk Tolerance pada Pemilihan Jenis Investasi. Journal of Business and Banking, 5(2), 271-282. https://doi.org/10.14414/jbb.v5i2.548 
Putri, \& Hamidi, M. (2019). Pengaruh literasi keuangan, efikasi keuangan, dan faktor demografi terhadap pengambilan keputusan investasi (studi kasus pada mahasiswa magister manajemen. Jim.Unsyiah.Ac.Id, 4(1), 398-412. Retrieved from http://www.jim.unsyiah.ac.id/EKM/article/view/10703

Putri, \& Rahyuda, H. (2017). Pengaruh Tingkat Financial Literacy Dan Faktor Sosiodemografi Terhadap Perilaku Keputusan Investasi Individu. E-Jurnal Ekonomi Dan Bisnis Universitas Udayana, 9, 3407. https://doi.org/10.24843/eeb.2017.v06.i09.p09

Rakhmatulloh, A. D., \& Asandimitra, N. (2019). Pengaruh Overconfidence, Accounting Information, dan Behavioural Motivation Terhadap Keputusan Investasi di Kota Surabaya. Jurnal Ilmu Manajemen (JIM), 7, 796-806.

Sari, D. R. (2017). Pengaruh Literasi Keuangan, Pendapatan, dan Pendidikan Terhadap Keputusan Investasi Keluarga Etnis China di Surabaya. Journal of Business and Banking.

Setiawan, Y. C., Atahau, A. D. R., \& Robiyanto, R. (2018). Cognitive Dissonance Bias, Overconfidence Bias dan Herding Bias dalam Pengambilan Keputusan Investasi Saham. AFRE (Accounting and Financial Review), 1(1), 17-25. https://doi.org/10.26905/afr.v1i1.1745

Shabgou, M., \& Mousavi, A. (2016). Behavioral Finance: Behavioral Factors Influencing Investors' Decisions Making. Advanced Social Humanities and Management, 3(1), 1-6. https://doi.org/10.1006/anbe.1993.1255

Statman, M. (2008). What Is Behavioral Finance? Handbook of Finance, 79-84. https://doi.org/10.1002/9780470404324.hof002009

Subash, R. (2012). Role of Behavioral Finance in Portfolio Investment Decisions: Evidence from India. Faculty of Social Science Institute of Economic Studies, 8-9. Retrieved from http://ies.fsv.cuni.cz/default/file/download/id/20803

Ullah, S. (2015). An Empirical Study of Illusion of Control and Self-Serving Attribution Bias, Impact on Investor's Decision Making: Moderating Role of Financial Literacy. Research Journal of Finance and Accounting, 6(19), 109-118.

Waweru, N. M., Munyoki, E., \& Uliana, E. (2008). The effects of behavioural factors in investment decision-making: a survey of institutional investors operating at the Nairobi Stock Exchange. International Journal Business and Emerging Markets, 1(1), 24-41. https://doi.org/10.1504/IJBEM.2008.019243

Wulandari, D. A., \& Iramani, R. (2014). Studi Experienced Regret, Risk Tolerance, Overconfidance Dan Risk Perception Pada Pengambilan Keputusan Investasi. Journal of Business and Banking, 4(1), 55. https://doi.org/10.14414/jbb.v4i1.293 